Originally published as:

Leendertz, S.A.J., Metzger, S., Skjerve, E., Deschner, T., Boesch, C., Riedel, J., Leendertz, F.H. A longitudinal study of urinary dipstick parameters in wild chimpanzees (Pan troglodytes verus) in Côte d'ivoire (2010) American Journal of Primatology, 72 (8), pp. 689-698.

DOI: 10.1002/ajp.20825

This is an author manuscript.

The definitive version is available at: http://onlinelibrary.wiley.com/ 


\title{
A Longitudinal Study of Urinary Dipstick Parameters in Wild Chimpanzees (Pan troglodytes verus) in Côte d'Ivoire
}

\author{
Siv Aina J. Leendertz ${ }^{1,2,3 *}$, Sonja Metzger ${ }^{1,2}$, Eystein Skjerve ${ }^{3}$, Tobias Deschner $^{1}$, \\ Christophe Boesch ${ }^{1}$, Julia Riedel ${ }^{1}$, and Fabian H. Leendertz ${ }^{1,2}$ \\ ${ }^{1}$ Max Planck Institute for Evolutionary Anthropology, Deutscher Platz, Leipzig, Germany \\ ${ }^{2}$ Robert Koch-Institut, Nordufer, Berlin, Germany \\ ${ }^{3}$ Norwegian School of Veterinary Science, Oslo, Norway \\ Contract grant sponsors: Max Planck Institute for Evolutionary Anthropology; Chester Zoo.
}

*Correspondence to: Siv Aina J. Leendertz, Robert Koch-Institut, Research Group Emerging Zoonoses, Nordufer 20, 13353 Berlin, Germany. E-mail: LeendertzS@rki.de

We performed 796 dip-stick tests on urine from 100 wild West African chimpanzees (Pan troglodytes verus) from 4 habituated groups in the tropical rain forest of Taï National Park, Cote d'Ivoire, to establish reference values for health monitoring. Specific gravity was also measured on 359 urine samples from 62 chimpanzees. The effect of age, sex, group, month, estrus, pregnancy, meat consumption, and acute respiratory disease on $\mathrm{pH}$, leucocytes, protein, blood, hemoglobin, and glucose was examined using ordinal logistic regression. The presence of nitrite, ketones, bilirubin, and urobilinogen in urine was also recorded. Outbreak of acute respiratory disease did not influence any of the urinary parameters. Thirty-seven percent of the samples had a $\mathrm{pH}$ o7 and the whole range of $\mathrm{pH}$ was found through the year, in all age groups, and in both sexes. Meat consumption lowered the urinary $\mathrm{pH}$. Our results show that all $\mathrm{pH}$ levels must be considered normal for the West African chimpanzee subspecies $P$. troglodytes verus living in the rainforest. We also found a cluster of glucose-positive samples at a specific point in time which was not attributed to diabetes mellitus. These findings highlight that there are differences in normal physiological parameters among wild chimpanzees living in different habitats.

\section{Introduction}

Infectious diseases, together with poaching and habitat destruction, threaten the survival of chimpanzees living in the few remaining tropical forests of the world. As populations are declining, it is essential to evaluate the health status for the conservation of these endangered species. Therefore, health monitoring is becoming increasingly more important in research and conservation work [Leendertz et al., 2006; Lonsdorf et al., 2006].

Health monitoring mainly relies on non-invasive methods, as anesthesia presents a risk for the animals and could have negative impacts on behavioral

fieldwork and conservation efforts. Monitoring is restricted to observations of clinical signs and the use of natural excreta, such as saliva, urine, and feces, as possible sampling material to describe physiological processes or possible disease occurrence in the groups. In the event of death, necropsy samples can be collected. Examples of non-invasive investigation are antibody and antigen extraction from urine and feces [Gillespie et al., 2008], and estimation of body temperature from faces temperature decline [Jensen et al., 2009]. Considering these limitations, it is important to develop new non-invasive methods and create baseline data specific for the chimpanzees for methods that already exist.

Urinary dip sticks measure $\mathrm{pH}$ and the presence of leucocytes, protein, blood, hemoglobin, glucose, nitrite, ketones, bilirubin, and urobilinogen. They provide rapid screening mainly for diseases of the kidney and the urogenital tract, carbohydrate metabolism disorders (diabetes mellitus), liver diseases, and hemolytic disorders. The dip sticks are widely used in human and veterinary medicine; however, their use is not yet well documented for wild primates in general, and only a few studies contribute to baseline data on urinary parameters in wild chimpanzees [Beaman et al., 2009; Kaur \& Huffman, 
2004; Kelly et al., 2004; Knott, 1998; Krief et al., 2005; Sleeman \& Mudakikwa, 1998]. Furthermore, the studies on chimpanzees include a relatively low number of samples collected from a limited number of months of the year, and provide data on the East African subspecies only. There has been no systematic, long-term collection of wild chimpanzee urinary parameters, and further, no baseline data exist on urinary parameters of the West African rainforestdwelling chimpanzee subspecies Pan troglodytes verus. It is possible that chimpanzee populations living in different habitats show differences in the urinary parameters, so reference values from one population might not fit another. For example, the studies of East African savannah chimpanzees all agree that urine from healthy individuals is highly alkaline as a result of their vegetarian diet [Kaur \& Huffman, 2004; Kelly et al., 2004; Krief et al., 2005]. In humans, a diet rich in meat lowers the urinary pH [Welch et al., 2007]. As the Taï chimpanzees frequently hunt small primates [Boesch \& Boesch-Achermann, 2000], we wanted to investigate if meat consumption lowers urinary $\mathrm{pH}$ and to determine the normal range of urinary $\mathrm{pH}$ in these chimpanzees.

The aim of our study was to investigate urinary parameters of West African chimpanzees ( $P$. troglodytes verus) collected from 55 months over a 7-year period, in order to establish well documented urinary reference data for future health monitoring. We wanted to estimate the effect of demographic factors, such as age, sex, group, month, and meat consumption, as well as physiological changes during estrus and pregnancy, on urine parameters. We further wanted to investigate if respiratory disease, a well recognized cause of death in wild chimpanzees [Hanamura et al., 2008; Kondgen et al., 2008; Kuehl et al., 2008] had an effect on urine parameters.

\section{Methods}

\section{Study Site and Population}

Four groups (South, North, Middle, and East) of wild chimpanzees (P. troglodytes verus) in the tropical rain forest of Taï National Park (51150-61070N, 71250-71540W), Côte d'Ivoire, have been habituated to human presence for up to 30 years [Boesch \& Boesch-Achermann, 2000]. The chimpanzees are individually recognized and are observed daily by researchers and assistants for behavioural research, and since 2001, a continuous animal health program has been in place [Leendertz et al., 2006]. The groups live in slightly overlapping territories of up to approximately $25 \mathrm{~km} 2$ [Herbinger et al., 2001]. The climate at the study site is characterized by two rainy seasons (March-June and SeptemberOctober), with an annual rainfall of approximately $1,800 \mathrm{~mm}$ and mean monthly temperature from 24 to 281C [Boesch \& Boesch, 1983].

At the beginning of this study in 2001, there were 52, 24, and 11 chimpanzees in the South, North, and Middle group, respectively. Habituation of the East group is still ongoing; this group contained about 50 individuals at the beginning of 2008. The exact age is known for the majority of the chimpanzees, whereas for the older chimpanzees the age was estimated at the time of identification. The individuals were divided into age groups: infants (up to 5 years), juveniles (up to 10 years), subadults (up to 15 years), adults (up to 35 years), and old adults (35 years and older) [Boesch \& Boesch-Achermann, 2000; Goodall, 1986].

\section{Sampling Strategy}

Urine samples for urinary dipstick testing were collected between May 2001 and April 2008, except from September 2002 to June 2004 when field data collection was discontinued, primarily owing to civil unrest in the country. Samples were collected ad libitum when the situation allowed; hence, there was a great variation in the number of samples collected per individual, group, and month. Dipstick results were obtained for 100 chimpanzees. During the last 20 months of the study, specific gravity (SG) was measured in urine from 62 chimpanzees. One hundred and three chimpanzees were included in the study: 61 chimpanzees (33 females, 28 males) from the South group, 23 chimpanzees (15 females, 8 males) from the North group, 8 chimpanzees (3 females, 5 males) from the Middle group, and 11 chimpanzees ( 4 females, 7 males) from the East group.

\section{Urinary Sample Collection}

Urine samples were collected immediately after urination from vegetation, rocks, or tree trunks with a single use micropipette and stored in $2 \mathrm{ml}$ tubes. Only urine uncontaminated by feces and soil were collected. The name of the chimpanzee, time, and date of urination were recorded for each sample. For females over 10 years, the presence of estrus (determined by maximal anogenital swelling) was retrieved from the project's data base and pregnancy status was determined by human urinary 
pregnancy test (Viola-C, CARE diagnostica, Austria) or estimated from birth of off-spring. Date and time of successful hunts and which chimpanzees consumed meat were retrieved from the project's data base. Furthermore, it was recorded if the sample had been collected during an outbreak of acute respiratory disease in the respective group and if the sample came from a chimpanzee with clinical signs of respiratory disease.

\section{Dip Stick Testing and Measuring of Specific Gravity}

Urinary dip sticks tests (Combur test [Roche, Basel, Switzerland] or Multistix [Bayer, Leverkusen, Germany]) tests were performed in the field within $30 \mathrm{~min}$ after collection of the urine samples. The tests were read by veterinarians or project assistants according to manufacturers' instruction and the result for each parameter was determined by visual color changes of the test pads. Doubleblind tests were performed in order to assure comparability of data. The $\mathrm{pH}$ and the presence of leucocytes, protein, blood, hemoglobin, glucose, nitrite, ketones, urobilinogen, and bilirubin were recorded. For the statistical analyses, all pH results ending with 0.5 were rounded upwards (37 samples), and the results for each parameter were made into 5 categories (0-4) to get similar ordinal responses levels for all parameters. The SG was measured with a hand-held refractometer (Kruuse, Denmark) calibrated against distilled water.

The urinary dip stick tests are semi-quantitative, thus adjustment for the SG of the urine is not required for clinical use of the test. However, if the SG is available, it should be considered in the clinical evaluation of the urinary parameters, in particular for protein as it is important to estimate the amount of protein loss in the case of renal damage [Newman et al., 2000]. In our study, SG was available for only one-third of the dip stick results, so no adjustment could be made.

\section{Statistical Analyses}

The database was established in Excels for Windows before being transferred to Stata (Stata/SE 10.0 for Windows, Stata Corp, College Station, TX). Data for each dipstick parameters were analyzed using cross-tables and histograms. Further statistical analyses were undertaken only for parameters showing some degree of variability: $\mathrm{pH}$, leucocytes, protein, blood, hemoglobin, and glucose. For these parameters, the effect of age, sex, group, month, meat consumption, acute respiratory disease in the group, and presence of clinical signs of respiratory disease in individual chimpanzees was examined using ordinal logistic regression, whilst adjusting for possible differences between the two brands of dipstick test, and to some degree between test readers (the data were divided into four main reader groups) by including these variables in the statistical model building. The ordinal logistic model calculates the probability of being classified in each level of the ordinal variable, given the specific set of covariates. One way of expressing the effect level is to use the Odds Ratio (OR). An OR 41 indicates that an increasing level of covariates leads to a higher response, and an OR between 0 and 1 a lower response. Comparing groups, an OR 41 means that the reference group has lower levels of the ordinal variable. The software also returns an approximate R2 (coefficient of determination) in the form of the pseudo R2. Model building is similar to that for the logistic model, using the likelihood ratio test to select between models.

For glucose, a full statistical model did not converge owing to the many zero levels, so a reduced model, including the predictor variables sex, age, and reported acute respiratory disease in group, and individual chimpanzees showing signs of respiratory disease, was used for this parameter. For the same reason, the predictor variable group was not included in the statistical model for hemoglobin. Owing to the repeated measurements, the individual chimpanzees were entered as a random effect in the regression models. Model fit was assessed using standard procedures based upon comparing predicted probabilities to observed frequencies for each combination of covariates. One subset of the data (females more than 10 years of age) was analyzed for the effect of estrus and pregnancy on the same parameters. For SG, we used linear regression with individual chimpanzee as a random effect, to assess the effect of the same factors as above, apart from respiratory disease as no outbreak occurred during the time when SG was measured.

\section{Approval of Research Protocols}

All samples were collected noninvasively, without disturbance to the chimpanzees; and research adhered to the American Society of Primatologists Principles for the Ethical Treatment of Nonhuman Primates. Research protocols were reviewed and approved by the Ministry of Research of Côte d'Ivoire, the Office Ivoirienne des Parcs et Reserves, and the Max Planck Society, Germany, and adhered to the legal requirements of the Côte d'Ivoire (Ministry of Research of Côte d'Ivoire and the Office Ivoirienne des Parcs et Reserves). 


\section{Results}

\section{Urinary Dip Sticks}

Tests were performed on 796 urine samples (619in South, 131 in North, 37 in Middle, and 9 in East). Of these, there were 429 samples from females, 367 from males; 59 samples from 18 females in estrus; 58 samples during 15 pregnancies; 26 samples were collected from 17 individuals between 12 and $36 \mathrm{hr}$ after meat consumption; and 33 samples were collected from 14 individuals during acute respiratory outbreaks in the South group, of which 20 samples were collected from 9 individuals with clinical signs of respiratory disease. The median number of tests for each month of the year was 68 (range 36-113). An overview of the test results of the individual parameters is given in Table I. As can be seen, only $\mathrm{pH}$, leucocytes, protein, blood, hemoglobin, and glucose showed considerable variability.

\section{$\mathrm{pH}$}

Of all samples, $37 \%$ were acidic and $53 \%$ were alkaline. The whole range of $\mathrm{pH}$ levels were found throughout the year as well as in all age groups and in both sexes. There was a strong monthly variation with relatively low levels from September to November and relatively high levels in March, April, and July, compared with small monthly variation for the other parameters (Fig. 1). The pH levels were lower in chimpanzees that had eaten meat $12-36 \mathrm{hr}$ before sampling, compared with all other samples (OR=2.6, $\mathrm{P}=0.002$; see Fig. 2). Levels of $\mathrm{pH}$ were not affected by sex, estrus, pregnancy, or acute respiratory disease in individuals or in the group. A small age effect was found; the subadult age group had higher $\mathrm{pH}$ levels compared with the infants $(\mathrm{OR}=2.1, \mathrm{P}=0.022)$, adults $(\mathrm{OR}=1.7, \mathrm{P}=0.028)$, and old adults $(\mathrm{OR}=1.9, \mathrm{P}=0.020)$, whereas there were no differences between any of the other age groups. The North group had lower $\mathrm{pH}$ levels compared with the South group (OR=1.5, $\mathrm{P}=0.033$ ), whereas there was no difference between any of the other groups. Overall, the month of the year was the decisive variable for $\mathrm{pH}$. The statistical model explained $10 \%$ (pseudo R2) of the variation in $\mathrm{pH}$.

\section{Leucocytes}

Females had significantly higher levels of leucocytes than males $(\mathrm{OR}=4.4, \quad \mathrm{P}<0.001)$. Older chimpanzees generally had higher levels than younger ones, in that there were higher levels of leucocytes in the old adults compared with the youngest age groups $(\mathrm{OR}=2.9, \mathrm{P}=0.001$; $\mathrm{OR}=2.1$, $\mathrm{P}=0.018 ; \mathrm{OR}=2.1, \mathrm{P}=0.002$ for old adults compared with infants, juveniles, and subadults, respectively). There was no difference between the adults and the old adults and between the infants, juveniles, and subadults. Levels were lower in the North group compared with the South group $(\mathrm{OR}=1.5, \mathrm{P}=0.033)$, whereas there were no differences between any of the other groups. The level of leucocytes was not affected by meat consumption, estrus, pregnancy, or acute respiratory disease in individuals or in the group. The statistical model explained $17 \%$ of the variation in leucocyte levels.

\section{Protein}

Protein levels were higher in females than in males $(\mathrm{OR}=1.8, \mathrm{P}=0.001)$, and there was a trend for higher levels in pregnant than in nonpregnant females $(\mathrm{OR}=2.0, \mathrm{P}=0.057)$. The levels were lower in the North group compared with the South group $(\mathrm{OR}=3.5, \mathrm{P}=0.006)$, whereas there was no difference between any of the other groups. The level of protein was not affected by age, meat consumption, estrus, or acute respiratory disease in individuals or in the group. The statistical model explained $19 \%$ of the variation in protein levels.

\section{Blood}

Older chimpanzees generally had higher levels of blood than younger ones, in that the oldest age group had higher levels compared with all the younger age groups $(\mathrm{OR}=2.3, \mathrm{P}=0.054$; $\mathrm{OR}=4.0$, $\mathrm{P}=0.001 ; \mathrm{OR}=5.4, \mathrm{P}<0.001 ; \mathrm{OR}=2.1, \mathrm{P}=0.010$ when compared with infants, juveniles, subadults, and adults, respectively), and the adults had higher levels compared with the subadults (OR=2.6, $P=0.012)$. For females in estrus, the blood levels was marginally higher than in nonestrus females $(\mathrm{OR}=2.4, \mathrm{P}=0.082)$. The level of blood was not affected by sex, meat consumption, pregnancy, or acute respiratory disease in individuals or in the group. None of the nine samples from East group were positive for blood. Overall, there were no differences between the three other groups. The statistical model explained $11 \%$ of the variation in blood levels.

\section{Hemoglobin}

Females had higher hemoglobin levels than males ( $\mathrm{OR}=1.7, \mathrm{P}=0.029)$, and older chimpanzees generally had higher levels than the younger ones $(\mathrm{OR}=2.3, \mathrm{P}=0.027$; $\mathrm{OR}=2.2, \mathrm{P}=0.039$ for old adults compared with juveniles and subadults, respectively, and for adults $\mathrm{OR}=2.2, \mathrm{P}=0.031 ; \mathrm{OR}=2.0$, 
$\mathrm{P}=0.079$ compared with juveniles and subadults, respectively). Higher levels were found in the Middle group compared with the South and North group ( $\mathrm{OR}=2.5, \mathrm{P}<0.001$; $\mathrm{OR}=3.7, \mathrm{P}=0.000$, respectively), and higher levels in East group as compared with the North group ( $\mathrm{OR}=8.2, \mathrm{P}=0.037)$. There were no differences between any of the other groups. The level of hemoglobin was not affected by meat consumption, estrus, pregnancy, or acute respiratory disease in individuals or in the group. The statistical model explained $9 \%$ of the variation in hemoglobin levels.

\section{Glucose}

Apart from one sample collected in the East group, all positive glucose samples were found in North and South. Of these samples, three were positive for ketones. The positive glucose samples were mainly found in 3 clusters for the 2 groups: 30 samples from 15 North chimpanzees from October to December 2005, 6 samples from 5 South chimpanzees from August to November 2005, and 5 samples from 1 North chimpanzee in October 2006. Higher levels were found in the infant group compared with the juveniles, adults, and old adults $(\mathrm{OR}=4.2, \mathrm{P}=0.050 ; \mathrm{OR}=4.2, \mathrm{P}=0.022 ; \mathrm{OR}=11.1$, $P<0.001)$, respectively, and subadults had higher levels than old adults $(O R=4.3, P=0.037)$. The level of glucose was not affected by meat consumption, sex, estrus, pregnancy, or acute respiratory disease in individuals or in the group. The statistical model explained $4 \%$ of the variation in glucose levels.

\section{Other Parameters}

Twenty-three samples from 11 females and 5 males were positive for nitrite, and 11 samples were also positive for leucocytes. All urobilinogen tests were negative. Sixty-six samples from 25 females and 21 males were positive for bilirubin, with $82 \%$ of these at the lowest positive value. Low-level bilirubin was found in all but 1 calendar month, and no seasonal pattern was found for either low and/or high values of bilirubin. No chimpanzee had more than three positive samples.

Twenty-six samples from 8 males and 8 females were positive for ketones. Eleven of these samples (from 8 chimpanzees older than 10 years), including 6 samples with high levels, were collected in January and February 2002. All samples with high values came from males, apart from 1 sample which was from a female with a 3 year old offspring. One female in early lactation and one heavily pregnant female had low ketone values. Five low positive samples were collected from one orphaned infant in October and November 2006.

There was a moderate correlation between blood and hemoglobin ( $r 50.41)$, otherwise there was no significant correlation between any of the other dip stick parameters. There was no correlation between time of urination and any of the parameters.

\section{Specific Gravity}

Three hundred and fifty-nine SG values were measured on urine from 62 chimpanzees (179 samples from males and 180 from females). Between 1 and 28 (median 4) samples were measured from each chimpanzee, and for each calendar month between 7 and 115 (median 23) samples were measured. The range of SG was between 1.000 and 1.050, and the mean value was 1.018 (SD50.012). The most common SG result was 1.001 ( $7.5 \%$ of the samples) and SG readings up to 1.003 accounted for $16.7 \%$ of the samples, whereas $9.7 \%$ of the samples were above 1.035 . For samples with SG above 1.035 (N535), urinary dipstick results were recorded for 19 samples, which were all negative for glucose and 9 samples had trace value of protein. There was a strong monthly variation with relatively low levels in the last 4 months of the year (Fig. 3). The mean value for infants was $0.009-0.013$ lower than all other age groups (P-values 00.001-0.003). Between the older age groups, there was no difference. SG was not affected by meat consumption, sex, group, estrus, or pregnancy. For 297 samples, both SG and dip stick results were recorded. Correlation between SG and dip stick parameters were generally low, but a weak (r50.29) correlation was found with protein. There was no correlation between SG and time of urination. 


\section{Discussion}

This study describes the effect of multiple demographic factors, time of year, and respiratory disease on urinary parameters of wild chimpanzees. This study is the first to describe urinary parameters in the West African chimpanzee subspecies, P. troglodytes verus.

\section{Urinary $\mathrm{pH}$}

One of our principal findings was a very wide range of $\mathrm{pH}$. Urinary $\mathrm{pH}$ reflects the internal homeostasis of the acid-base balance to keep a constant body $\mathrm{pH}$. It is not only a result of the total acid-base load of the diet, but can also be influenced by respiratory or metabolic acidosis/alkalosis [Hohenberger \& Kimling, 2008]. In contrast to what has been reported about chimpanzee as well as gorilla urinary $\mathrm{pH}$ before [Kaur \& Huffman, 2004; Kelly et al., 2004; Krief et al., 2005; Sleeman \& Mudakikwa, 1998], we found that acidic urine was almost as common as alkaline urine in the Taï chimpanzees. Urine from East African chimpanzees in the other studies was almost exclusively alkaline, and in those few cases where low urinary $\mathrm{pH}$ was recorded it was considered as a sign of poor health. In our study, there was no evidence that the urine $\mathrm{pH}$ decreased as a result of respiratory acidosis during outbreaks of acute respiratory disease, but it is possible that this effect has been masked by the fact that acidic urine was common throughout the study. However, we found the whole range of $\mathrm{pH}$ levels throughout the year as well as in all age groups and in both sexes. It is unlikely that there was any post-sampling change in $\mathrm{pH}$, as the samples were tested immediately after collection; therefore, the wide range of $\mathrm{pH}$ results represents the true spectrum of urinary $\mathrm{pH}$ in the chimpanzees. A wide range of urinary $\mathrm{pH}(5-9)$ is normal in healthy humans and captive chimpanzees [Hohenberger \& Kimling, 2008; S. Unwin, personal communication], but has not earlier been reported for wild chimpanzees. In humans, a diet rich in meat lowers the urinary $\mathrm{pH}$ [Welch et al., 2007]. We found that this is also evident for wild chimpanzees, as the urinary $\mathrm{pH}$ decreased after meat consumption. Also, the months with relatively low mean urinary $\mathrm{pH}$ correspond to the Taï chimpanzees' hunting season [Boesch \& BoeschAchermann, 2000]. During this time of the year, the chimpanzees usually hunt every day, whereas for the rest of the year they hunt on average once a week. Meat eating is also observed at the sites where earlier studies on chimpanzee urine parameters were undertaken [Ghiglieri, 1984; Nishida et al., 1979], but it is possible that the chimpanzees were not hunting shortly before urine sampling took place and, therefore, acidic urine was not reported.

However, meat is probably not the sole explanation for acidic urine in the Taï chimpanzees. Adding meat consumption into the statistical analyses improved the overall explanation of $\mathrm{pH}$ variation by less than $1 \%$. Of course, a number of successful hunts could have been missed, as all chimpanzees were not under observation at all times. Still, other food items may have played a role in acidifying urine, as urine with low $\mathrm{pH}$ was just as common in some months of the year as alkaline urine and overall represented $37 \%$ of the samples; in other words, acidic urine was too common to be caused by just meat consumption. Also, vegetarian foods, such as cranberries in the human diet, can acidify urine [Jackson \& Hicks, 1997]. We also considered ants and other insects as sources of animal protein that could lower urinary $\mathrm{pH}$ in the Taï chimpanzees, but this could not be determined by the available insect feeding data.

Our results show that it must be considered normal for the West African chimpanzee subspecies $\mathrm{P}$. troglodytes verus living in the rainforest to have a wide range of urinary $\mathrm{pH}$.

\section{Glucose}

Another finding was the relatively high number of positive glucose results. Glucose in urine is mainly an indicator of the disease diabetes mellitus, often together with high ketone levels [Hohenberger \& Kimling, 2008]. To the authors' knowledge, glucosuria has been reported in only one sample in other studies of wild chimpanzee urinary parameters [Krief et al., 2005]. We found that even high glucose levels were occasionally present in urine of some chimpanzees. According to the manufacturers, the dip sticks react specifically to glucose and no other substances found in urine; the glucose test is independent of the $\mathrm{pH}$ and SG of the urine, and is not affected by the presence of ketone bodies. Therefore, our positive test results should be truly positive. However, because glucosuria occurred in several individuals simultaneously at a specific point in time and the fact that most of the positive readings were not accompanied with positive ketone findings (high values of both glucose and ketones is a typical finding in diabetes mellitus), we believe that there must be another explanation for the positive glucose results other than diabetes mellitus. One possibility is that the chimpanzees had eaten large amounts of fruits with high sugar content which produced temporary hyperglycemia that has overridden the kidneys glucose threshold level [Hohenberger \& Kimling, 2008]. Some evidence for 
this is that the North chimpanzees fed on sweet fruits, such as Sacoglottis gabonensis, Nauclea diderrichii, and Irvingia grandifolia, during the months when many samples were positive for glucose in this group (A. Nguessan, personal communication). It is also possible that a specific type of fruit, leaf, seed, bark, or another part of a plant that the chimpanzees eat either as food or self-medication, causes temporary presence of glucose in their urine. More than 400 medicinal plants have been documented to have hypoglycemic properties, but the mechanism of hypoglycemic action is not known for all plants [Prabhakar \& Doble, 2008]. Some medicinal plants contain compounds, such as phlorizin, which inhibits renal glucose reabsorption and hence produce glucosuria [Ehrenkranz et al., 2005]. It is possible that one or more plants, either alone or in combination, could have had a similar effect on the Taï chimpanzees. During October-December 2005, when the largest cluster of positive glucose samples were found, the North group chimpanzees ate fruit and plant material from more than 50 different species as well as mushrooms, soil, ants, and primate meat (A. Nguessan, personal communication). We have not been able to pinpoint if any specific dietary constituent was the cause of glucosuria, as there are no individual feeding data from this time period. Furthermore, we could not find any feeding substance that was unique for this point in time. We hope our results will encourage future prospective studies to explore this phenomenon in the Taï chimpanzees and possibly other communities.

\section{Leucocytes, Protein, Blood, and Hemoglobin}

Of all the urinary parameters, leucocytes (white blood cells), which indicate an infection in the urogenital tract, were the most common positive test result (62\% of the samples positive). Protein (a frequent symptom in kidney disease) was also a common finding with $30 \%$ of the samples positive, but the results were almost exclusively trace value and, therefore, not consistent with kidney disease. A small amount of protein in the urine can occur intermittently in people with healthy kidneys (benign proteinuria) and is often caused by physical activity or fever [Kashif et al., 2003]. Proteinuria is also common in urinary tract infections [Carter et al., 2006]. We found that female chimpanzees had more leucocytes and protein than males, but this was for neither parameter owing to estrus, which indicates a higher degree of urinary and/or reproductive tract infection in females than in males in general. Leucocytes in female urine may also be owing to contamination of the specimen by vaginal discharge. The difference in sexes is also reflected in the higher number of samples positive for nitrate (which indicates urinary bladder infection) amongst females, even though there were relatively few positive nitrate samples. There was no overall correlation between nitrate and leucocyte levels. We also found that pregnancy increased the level of protein in the urine; such leakage of protein into the urine, as a result of normal physiological changes in the kidney, is well documented in humans [Maynard \& Thadhani, 2009]. The differences between the groups regarding leucocytes and protein, with higher levels in the South group compared with the North group, probably indicates a more frequent occurrence of urogenital tract infection and causes of benign proteinuria in the former group, but the reasons for this are unknown.

Females in estrus had marginally higher urinary blood levels compared with other females; otherwise, estrus did not affect any other parameters. In Taï, female chimpanzees in estrus will show maximum anogenital swelling between 6 and 18 days, and the blood detected by the urinary dip stick test during these days is likely to be caused by minor trauma to the vagina during copulation, or trauma to the swelling itself. Although the urinary blood levels were marginally higher in females with estrus swelling, there was overall no difference in the frequency of occurrence of blood in the urine samples between the sexes, but other causes of hematuria, such as urinary tract pathology or bladder parasites, kidney trauma owing to fighting, and physical stress, might even out the effect between the sexes. However, females had higher levels of haemoglobin than males, which in some cases could be owing to hemolysis of red blood cells in the urine and, therefore, reflect a true difference between males and females with regard to blood because there was a moderate correlation between these two parameters. The higher levels of hemoglobin in females could partly be explained by menses; however, our study did not specifically test for the presence of blood during the presumed days of menstruation.

Age was an important factor for the level of leucocytes, blood, and hemoglobin, in which they all generally increased with age for both sexes. This could be explained by sexual activity together with the accumulation of urogenital tract infection and other urogenital pathology, over time. However, protein was found equally in all age groups and, therefore, not affected by the above factors; and, as discussed above, only trace levels were found in most of the positive samples. When evaluating the protein level in a urine sample, one should consider the SG of the urine if this is available, as protein above trace value in urine with low SG (diluted urine) indicates a greater protein loss than in urine with higher SG [Newman et al., 2000]. In our study, the SG of the urine was only available for a third of the 
samples that had been tested with dip sticks, but the positive protein results were almost exclusively of trace value, so adjustment for SG would in any case be unnecessary from a clinical point of view.

\section{Ketones}

Ketones occur in the urine when an increased fat metabolism owing to insufficient supply of energy in the form of carbohydrates occur, such as in starvation [Hohenberger \& Kimling, 2008]. The largest cluster of positive samples occurred during January and February 2002. During the months of January and February, Taï chimpanzees rely heavily on nuts (Coula edulis) as their energy source [Boesch \& Boesch-Achermann, 2000] and we, therefore, initially considered that a possible shortage of nuts in that particular year could have caused a significant reduction in energy intake and hence ketonuria. However, data on phenology and chimpanzee feeding does not support this (data base Taï Chimpanzee Project/Christophe Boesch). We considered stressful events which might have occurred, but there was no change of alpha-male, physical encounters with neighboring chimpanzee communities, or major poaching occurring at this time. The reason for this cluster of positive ketone results remains unknown, whereas the second cluster of ketone-positive samples were collected from one recently orphaned infant who was observed to lose weight. There were, overall, few positive ketone results, including only one positive sample from a heavily pregnant female and one from a female in early lactation, and no seasonal pattern was detected. These results indicate that the chimpanzees' weight does not fluctuate enough for any weight loss to be detected by measuring urinary ketones, as has been shown in orangutans [Knott, 1998]. It seems that C-peptide, a urinary metabolite of insulin, is a better physiological marker of energetic condition in wild chimpanzees [Deschner et al., 2008; Thompson et al., 2009].

\section{Urobilinogen and Bilirubin}

Urobilinogen and bilirubin are indicators of liver pathology [Hohenberger \& Kimling, 2008]. In accordance with other studies on wild chimpanzees, we found no sample to be positive for urobilinogen [Kaur \& Huffman, 2004; Kelly et al., 2004; Krief et al., 2005]. This finding, together with the fact that bilirubin was found mainly in low levels, indicates that the chimpanzees probably did not suffer from serious, chronic hepatitis. However, $8 \%$ of the samples were positive for bilirubin and one cannot rule out the effect of liver pathology of shorter duration, such as malaria or acute phases of viraemic hepatitis infections, such as hepatitis $B$; both of which are known to occur in the Taï chimpanzees [Rich et al., 2009; F. Leendertz, unpublished data].

\section{Specific Gravity}

Our study shows a much wider range of urinary SG compared with what has earlier been reported for wild chimpanzees, although the mean SG of urine (1.018) was similar [Kelly et al., 2004]. More than $70 \%$ of the samples were in the same range as reported by Kelly et al. [2004], with a specific gravity between 1.005 and 1.035, but we also show that extremely diluted urine must be considered normal during some times of the year and also that wild chimpanzees are able to greatly concentrate their urine depending on the amount of water available. The mean SG was relatively low in the last 4 months of the year, which probably reflects the abundance of water in and after the main rainy season. The range of levels varied a lot within a given month, especially in January, where the range was from 1.001 to 1.049. The infants had lower urinary SG than all the other age groups, which has also been observed for chimpanzees in captivity [Eder, 1996]. This is likely owing to their kidneys' relatively lower ability to concentrate urine, which is also seen in human infants and children [Polacek et al., 1965], as well as the relatively higher fluid content of their diet when breast feeding.

It is, of course, possible that some of the very dilute samples were owing to sampling of rain water, but care has been taken to avoid this. Regarding the very concentrated samples, we are aware that determination of urine concentration by SG measured by refractometer has certain limitations owing to the underlying physical principles, and that proteinuria and glucosuria will increase SG of the sample [Chadha et al., 2001]. There was a moderate correlation between protein and SG, but most of the protein results were trace values and should, therefore, not interfere significantly with the SG. Furthermore, our samples with SG of more than 1.035, for which a dip stick result was available, were all negative for glucose and half of them contained protein of trace value only. We, therefore, assume that these substances were not the cause of high SG.

\section{General Discussion}

Outbreak of acute respiratory disease did not influence any of the urinary parameters (neither on the individual nor on the group level), and the urinary dip stick test, therefore, does not aid in the early diagnosis of such disease outbreaks. Still, it would be important to continue to monitor the urinary 
parameters during these outbreaks, as it is possible that there would be changes over time, especially considering that individuals with respiratory symptoms may be more prone to other health problems.

Clinical observations will probably continue to be the main part of wild ape health monitoring, but, considering the few medical interventions possible, the urinary dip stick test should not be discarded as a health monitoring tool for these species. It could further be used to detect biological differences between subspecies or populations living in different environments. In this study, we have screened the chimpanzee communities as a whole, but in the field it is important to consider the medical history of the individual chimpanzees and perform follow-up tests when required.

Based on clinical observations, we assumed that the chimpanzees were healthy at the time of the sample collection, unless present in a group of chimpanzees experiencing an outbreak of acute respiratory disease. However, chimpanzees often do not show any signs of disease or weakness early in the disease process, to avoid social problems and predatation [Boesch \& Boesch-Achermann, 2000]. Therefore, an unknown proportion of the samples collected over the many years of the study could have come from sick chimpanzees. The statistical models that were used explained between 4 and $19 \%$ of the variation in the levels of the key parameters, which means that there are a number of unknown factors

influencing the urinary parameters that have not been considered in this study, including subclinical infections of any kind. There are possible sources of errors for each urinary parameter [Hohenberger \& Kimling, 2008], and the limitations of the use of urinary dipsticks have been reviewed by Kaur and Huffman [2004]. In addition, one must keep in mind the effect of subjective reading of the test results by various veterinarians and project assistants. We have controlled for this as much as possible during testing and in the analyses.

\section{Conclusion}

In conclusion, our results show that it must be considered normal for the West African chimpanzee subspecies $\mathrm{P}$. troglodytes verus, living in the rainforest, to have a wide range of urinary $\mathrm{pH}$. We also found a cluster of glucose-positive samples at a specific point in time which was not attributed to diabetes mellitus, and that wild chimpanzees have a wide range of urinary SG. These findings highlight that there are differences in normal physiological parameters between wild chimpanzees living in different habitats which should be investigated further and that there is a need to establish a comparable baseline dataset with healthy chimpanzees for each population under study before certain observed levels of parameters can be interpreted as pathological.

Our long-term study provides reference values for urinary dipstick results in wild living West African chimpanzees $\mathrm{P}$. troglodytes verus, and add to the few existing reference values for chimpanzees in general.

\section{Acknowledgments}

We thank the Ivorian authorities for long-term support, especially the Ministry of Environment and Forests as well as the Ministry of Research, the directorship of the Taï National Park,Office Ivoirien des Parcs et Réserves, and the Swiss Research Centre in Abidjan. We also thank the field assistants of the Taï Chimpanzee Project and Dr. Anja Blankenburg for assistance in data collection. Samples were collected noninvasively without disturbance to the chimpanzees. Research adhered to the American Society of Primatologists Principles for the Ethical Treatment of Nonhuman Primates. Research protocols were reviewed and approved by the Ministry of Research of Côte d'Ivoire, the Office Ivoirienne des Parcs et Reserves, and the Max Planck Society, Germany, and adhered to the legal requirements of the Côte d'Ivoire (Ministry of Research of Côte d'Ivoire and the Office Ivoirienne des Parcs et Reserves). The study was funded by the Max Planck Institute for Evolutionary Anthropology, Leipzig, Germany. We thank Chester Zoo for funding the handheld refractometer. 


\section{References}

Beaman BA, Hesemeyer WJ, Dominy NJ, Savini T, Reichard UH. 2009. Sterile pyuria in a population of wild whitehanded gibbons (Hylobates lar). American Journal of Primatology 71:1-4.

Boesch C, Boesch-Achermann H. 2000. The chimpanzees of the Taï forest: behavioural ecology and evolution. Oxford: Oxford University Press. 316p.

Boesch C, Boesch H. 1983. Optimisation of nut-cracking with natural hammers by wild chimpanzees. Behaviour 83: 265-286.

Carter JL, Tomson CR, Stevens PE, Lamb EJ. 2006. Does urinary tract infection cause proteinuria or microalbuminuria? A systematic review. Nephrology Dialysis Transplantion 21:3031-3037.

Chadha V, Garg U, Alon US. 2001. Measurement of urinary concentration: a critical appraisal of methodologies. Pediatric Nephrology 16:374-382.

Deschner T, Kratzsch J, Hohmann G. 2008. Urinary C-peptide as a method for monitoring body mass changes in captive bonobos (Pan paniscus). Hormones and Behavior 54: 620-626.

Eder G. 1996. A longitudinal study of the kidney function of the chimpanzee (Pan troglodytes) in comparison with humans. European Journal of Clinical Chemistry and Clinical Biochemistry 34:889896.

Ehrenkranz JR, Lewis NG, Kahn CR, Roth J. 2005. Phlorizin: a review. Diabetes/Metabolism Research and Reviews 21: 31-38.

Ghiglieri M. 1984. The chimpanzees of the Kibale Forest: a field study of ecology and social structure. New York: Columbia University Press. 226p.

Gillespie TR, Nunn CL, Leendertz FH. 2008. Integrative approaches to the study of primate infectious disease: implications for biodiversity conservation and global health. American Journal of Physical Anthropology, Supplement 47:53-69.

Goodall J. 1986. The chimpanzees of Gombe: patterns of behavior. Boston: Harvard University Press. Hanamura S, Kiyono M, Lukasik-Braum M, Mlengeya T, Fujimoto M, Nakamura M, Nishida T. 2008. Chimpanzee deaths at Mahale caused by a flu-like disease. Primates 49:77-80.

Herbinger I, Boesch C, Rothe H. 2001. Territory characteristics among three neighboring chimpanzee communities in the Taï national park, Côte d'Ivoire. International Journal of Primatology 22:143-167.

Hohenberger EF, Kimling H. 2008. Compendium urinalysis: urinalysis with test strips. Germany: Roche Diagnostics. Jackson B, Hicks LE. 1997. Effect of cranberry juice on urinary PH in older adults. Home Healthcare Nurse 15:199-202.

Jensen SA, Mundry R, Nunn CL, Boesch C, Leendertz FH. 2009. Non-invasive body temperature measurement of wild chimpanzees using fecal temperature decline. Journal of Wildlife Disease 45:542-546.

Kashif W, Siddiqi N, Dincer AP, Dincer HE, Hirsch S. 2003. Proteinuria: how to evaluate an important finding. Cleveland Clinic Journal of Medicine 70:535-537, 541-544, 546-547.

Kaur T, Huffman MA. 2004. Descriptive urological record of chimpanzees (Pan troglodytes) in the wild and limitations associated with using multi-reagent dipstick test strips. Journal of Medical Primatology 33:187-196.

Kelly TR, Sleeman JM, Wrangham R. 2004. Urinalysis in free-living chimpanzees (Pan troglodytes schweinfurthii) in Uganda. The Veterinary Record 154:729-730.

Knott CD. 1998. Changes in orangutan caloric intake, energy balance, and ketones in response to fluctuating fruit availability. International Journal of Primatology 19: 1061-1079.

Kondgen S, Kuhl H, N'Goran PK, Walsh PD, Schenk S, Ernst N, Biek R, Formenty P, Matz-Rensing K, Schweiger B, Junglen S, Ellerbrok H, Nitsche A, Briese T, LipkinWI, Pauli G, Boesch C, Leendertz FH. 2008. Pandemic human viruses cause decline of endangered great apes. Current Biology 18:260264.

Krief S, Huffman MA, Sevenet T, Guillot J, Bories C, Hladik CM, Wrangham RW. 2005. Noninvasive monitoring of the health of Pan troglodytes schweinfurthii in the Kibale National Park, Uganda. International Journal of Primatology 26:467-490.

Kuehl HS, Elzner C, Moebius Y, Boesch C, Walsh PD. 2008. The price of play: self-organized infant mortality cycles in chimpanzees. PLoS ONE 3:e2440.

Leendertz FH, Pauli G, Maetz-Rensing K, Boardman W, Nunn C, Ellerbrok H, Jensen SA, Junglen S, Boesch C. 2006. Pathogens as drivers of population declines: the importance of systematic monitoring in great apes and other threatened mammals. Biological Conservation 131:325-337.

Lonsdorf EV, Travis D, Pusey AE, Goodall J. 2006. Using retrospective health data from the Gombe chimpanzee study to inform future monitoring efforts. American Journal of Primatology 68:897-908.

Maynard SE, Thadhani R. 2009. Pregnancy and the kidney. Journal of the American Society of Nephrology 20:14-22. 
Newman DJ, Pugiab MJ, Lott JA, Wallace JF, Hiar AM. 2000. Urinary protein and albumin excretion corrected by creatinine and specific gravity. Clinica Chimica Acta 294:139-155.

Nishida T, Uehara S, Nyundo R. 1979. Predatory behaviour among wild chimpanzees of the Mahale Mountains. Primates 20:1-20.

Polacek E, Vocel J, Neugebauerova L, Ebkova M, Vechetova E. 1965. The osmotic concentration ability in healthy infants and children. Archives of Disease in Childhood 40:291-295.

Prabhakar PK, Doble M. 2008. A target based therapeutic approach towards diabetes mellitus using medicinal plants. Current Diabetes Review 4:291-308.

Rich SM, Leendertz FH, Xu G, LeBreton M, Djoko CF, Aminake MN, Takang EE, Diffo JL, Pike BL, Rosenthal BM, Formenty P, Boesch C, Ayala FJ, Wolfe ND. 2009. The origin of malignant malaria. Proceedings of the National Academy of Sciences of the United States of America 106:14902-14907.

Sleeman JM, Mudakikwa AB. 1998. Analysis of urine from free-ranging mountain gorillas (Gorilla gorilla beringei) for normal physiologic values. Journal of Zoo and Wildlife Medicine 29:432-434.

Thompson ME, Mullera MN, Wrangham RW, Lwangac JS, Pott KB. 2009. Urinary C-peptide tracks seasonal and individual variation in energy balance in wild chimpanzees. Hormones and Behavior 55:299-305.

Welch AA, Mulligan A, Bingham SA, Khaw KT. 2007. Urine pH is an indicator of dietary acid-base load, fruit and vegetables and meat intakes: results from the European prospective investigation into cancer and nutrition (EPIC)-Norfolk population study. British Journal of Nutrition 99:1335-1343. 


\section{Tables and Figures}

Table 1. Overview of Results of Urinary Dipstick Parameters from 796 Samples Shown as Categories

\begin{tabular}{|c|c|c|c|c|c|}
\hline Variable & Category 0 & Category 1 & Category 2 & Category 3 & Category 4 \\
\hline $\mathrm{pH}^{\mathrm{a}}$ & $113(5)$ & $185(6)$ & $75(7)$ & $162(8)$ & $260(9)$ \\
\hline Leukocytes (leu/pl) & 304 (neg) & $259(10-25)$ & $165(70-125)$ & $68(500)$ & - \\
\hline Protein (mg/dl) & 557 (neg) & $232(15-30)$ & $6(100)$ & $1(300-500)$ & - \\
\hline Blood (ery/ul) & 642 (neg) & $111(5-10)$ & $14(25)$ & $14(50-80)$ & $15(200-250)$ \\
\hline Hemoglobin (ery/ul) & 611 (neg) & $99(5-10)$ & $28(25)$ & $25(50-80)$ & $33(200-250)$ \\
\hline Glucose (mg/dl) & 749 (neg) & $15(50-100)$ & $4(250-300)$ & $0(500-1,000)$ & $28(1,600-2,000)$ \\
\hline Nitrite (pos/neg) & 773 (neg) & 23 (pos) & - & - & - \\
\hline Ketones (mg/dl) & 770 (neg) & $19(5-15)$ & $0(40-80)$ & $7(150-160)$ & - \\
\hline Urobilin (mg/dl) & $796($ neg- -0.2$)$ & $0(1)$ & $0(3-4)$ & $0(8-12)$ & - \\
\hline Bilirubine (mg/dl) & $730($ neg) & $54(2)$ & $9(4)$ & $3(6)$ & - \\
\hline
\end{tabular}

The actual values of the test result are shown in brackets.

ane value missing.

Figure 1. Monthly means of selected variables from urinary dipstick measurements. For the actual values of the categories, see Table I.

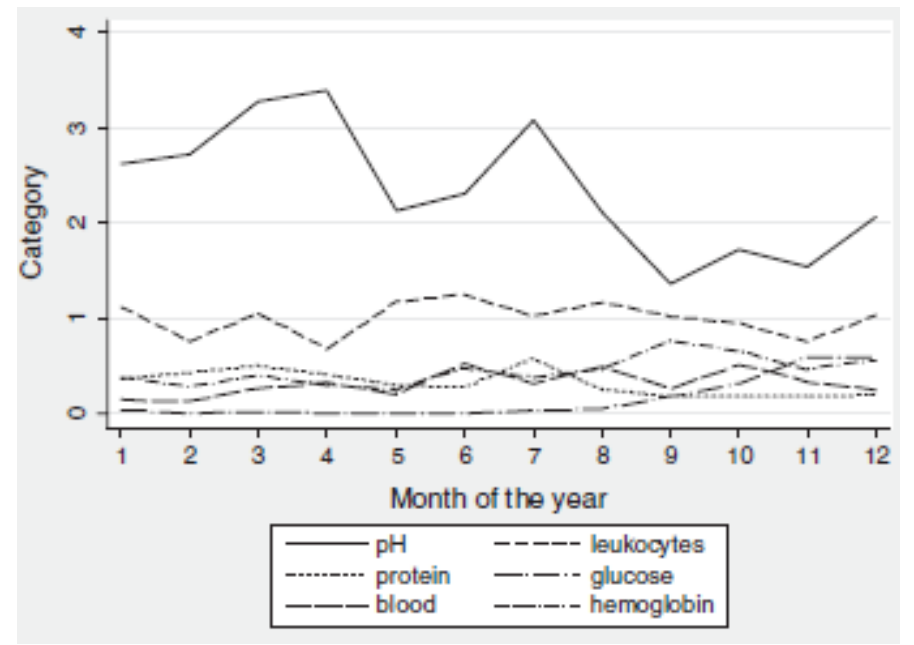

Figure 2. Urinary $\mathrm{pH}$ after meat consumption: comparison between samples collected $12-36 \mathrm{hr}$ after meat consumption and all other samples.

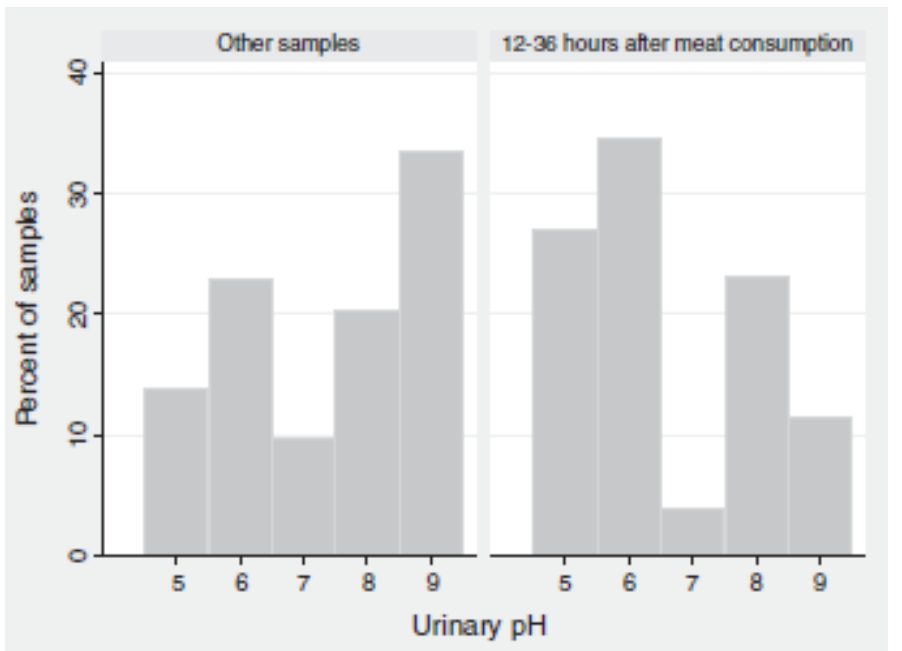


Figure 3. Monthly variation in mean urinary specific gravity (N5359).

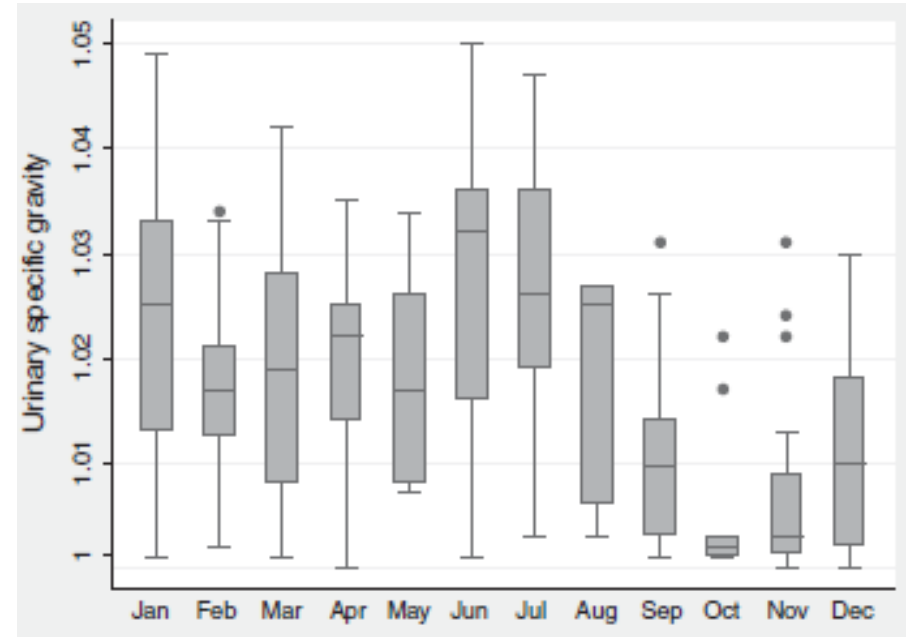

